\title{
Study of a hydraulic system converting energy from sea waves near the coast
}

\author{
Silvio Barbarelli, Mario Amelio, Gaetano Florio, and Nino Michele Scornaienchi \\ Department of Mechanical, Energy and Management Engineering (DIMEG) \\ University of Calabria - Ponte P. Bucci, cube 44/c, I87036 Rende, Italy
}

\begin{abstract}
This paper proposes a system able to recover energy from sea waves. The system is made up essentially of a floating structure, connected to a piston pump. The pump, constrained to move vertically under the action of the waves, pushes water into a reservoir maintained at constant pressure, from which it flows in a Pelton turbine. A methodology was developed for the preliminary sizing of the proposed system. This methodology takes the height of the waves and the pressure of the reservoir as reference parameters and then provides the main geometric data of the machines. A case study developed in the present work, demonstrates the possibility of designing miniaturized components of the system, able anyway to provide acceptable energy output with contained installation costs.
\end{abstract}

\section{Nomenclature}

\begin{tabular}{ll}
$A_{\text {buoy }}$ & buoyant area \\
$b$ & viscous damping coefficient \\
$A_{P}$ & piston area \\
$C_{o}$ & pump stroke \\
$c_{o}$ & spouting velocity \\
$C W R$ & capture width ratio \\
$D_{\text {buoy }}$ & characteristic size of the buoy \\
$D_{n}$ & nozzle diameter \\
$D_{P}$ & piston diameter \\
$D_{T}$ & turbine diameter \\
$F_{A}$ & Archimedes's force \\
$F_{w}$ & weight force \\
$F_{p}$ & pressure force \\
$g$ & gravity \\
$H_{m}$ & reservoir pressure \\
$H_{w}$ & wave height \\
$J$ & average wave power \\
$k$ & specific turbine speed \\
$m_{a d d}$ & added mass \\
$m_{b}$ & buoyant mass \\
$N_{c y}$ & wave frequency \\
$n_{T}$ & turbine rotational speed \\
$P_{P}$ & pump power \\
$P_{S y s t e m}$ & system power \\
$P_{T}$ & turbine power \\
$Q_{P}$ & pump flow rate \\
$Q_{T}$ & turbine flow rate \\
$T_{e}$ & wave period \\
$u$ & peripheral velocity \\
$V_{P}$ & pump volume \\
$V_{z}$ & sunk buoy volume \\
$z$ & vertical position of the buoy \\
& \\
\hline & \\
\hline &
\end{tabular}

$$
\begin{array}{ll}
z_{A} & \text { pressure sinking of the buoy } \\
z_{w} & \text { weight sinking of the buoy }
\end{array}
$$

\begin{tabular}{lll}
{$\left[\mathrm{m}^{2}\right]$} & \multicolumn{2}{l}{ Greek letter } \\
{$[\mathrm{kg} / \mathrm{s}]$} & $\beta$ & deflection turbine blade angle \\
{$\left[\mathrm{m}^{2}\right]$} & $\varphi$ & velocity reduction coefficient \\
{$[\mathrm{m}]$} & $\eta_{e l}$ & electrical efficiency \\
{$[\mathrm{m} / \mathrm{s}]$} & $\eta_{P}$ & pump efficiency \\
{$[\%]$} & $\eta_{T}$ & turbine efficiency \\
{$[\mathrm{m}]$} & $\rho$ & water density \\
{$[\mathrm{m}]$} & $\psi$ & velocity reduction coefficient
\end{tabular}

$[\mathrm{N}]$

$[\mathrm{N}]$

$[\mathrm{N}]$ $\left[\mathrm{m} / \mathrm{s}^{2}\right]$

$[\mathrm{m}]$

[m]

[kW/m]

$[-]$

[kg]

[kg]

$\left[\mathrm{min}^{-1}\right]$

[rpm]

[kW]

[kW]

[kW]

$\left[\mathrm{m}^{3} / \mathrm{s}\right]$

$\left[\mathrm{m}^{3} / \mathrm{s}\right]$

[s]

[m/s]

$\left[\mathrm{m}^{3}\right]$

$\left[\mathrm{m}^{3}\right]$

[m]

Keywords: Wave Energy, Point Absorber, Piston Pump, Pelton Turbine, Sizing Procedure, Specific Power, Pressure Control.

\section{Introduction}

Renewable energy sources are considered the way to unlock energy transition positively affecting the National Power Grid performance [1] by supplying natural driven energy such as solar, wind and marine [2]. Among marine resources, ocean waves are one of the most promising sources of renewable energy with an estimated potential of 2 TW around the world [3].

Waves are generated by bodies moving on or near the surface of the ocean, winds, seismic disturbances, and lunar and solar gravitational fields. The most common types of waves considered for engineering analysis are those created by the wind or swells [4]. Point absorbers 
are floating wave energy converters (WEC's) whose dimensions are much smaller than the wave length. These devices can oscillate, under the waves action, with one or more degrees of freedom. A point absorber is able to absorb wave energy from a wave front greater than the physical dimensions of the device itself [5]. After assessing the waves energy available at a particular site, an appropriate WEC can be designed which can be located offshore or inshore [6], according to the seabed characteristics. Furthermore, it can be coupled to storage systems to solve the mismatch between energy production and actual use [7].

Anyway, wave energy conversion technology is in the pre-commercial stage. The cost of a wave energy converter increases with its size. Therefore, the geometry optimization of the system has a significant role in the design process to make for an economically feasible system. A solution should be provided by the design of miniaturized components of the energy transformation mechanism, by leaving the dimensions of the point absorber relatively large.

In the present paper, the authors, inspired by the work of Paula B. Garcia-Rosa [8] propose a system whose point absorber (floating structure) is connected directly to a piston pump, which in turn delivers water to a pressurized reservoir.

The reservoir feeds a small Pelton turbine, able to provide power, determined by the available water flow and by the reservoir pressure, this last depending on the wave height.

The sizing methodology of the system is described, by pointing out the off-design operations and the management of the pressurized reservoir.

A study case demonstrated that the components can be designed with small dimensions, consequently containing the installation costs [9].

\section{Waves motion}

The waves motion constitutes a huge quantity of energy, currently exploited only in minimal part.

According to linear wave theory, by indicating with $H_{w}$ and $T_{e}$ height and period, the average power, transported by a wave per meter wave front is described by the following equation:

$$
J=\frac{\rho g^{2}}{32 \pi} \frac{T_{e} H_{w}^{2}}{1000}
$$

while the capture width ratio $(C W R)$ of the point absorber is defined as:

$$
C W R=100 \frac{P_{a v}}{J D_{\text {buoy }}}
$$

$P_{a v}$ and $D_{b u o y}$ being the average power and diameter of the point absorber.

As an example, in the next figure the potential of energy related to the Mediterranean sea, near to Pantelleria island, is reported.

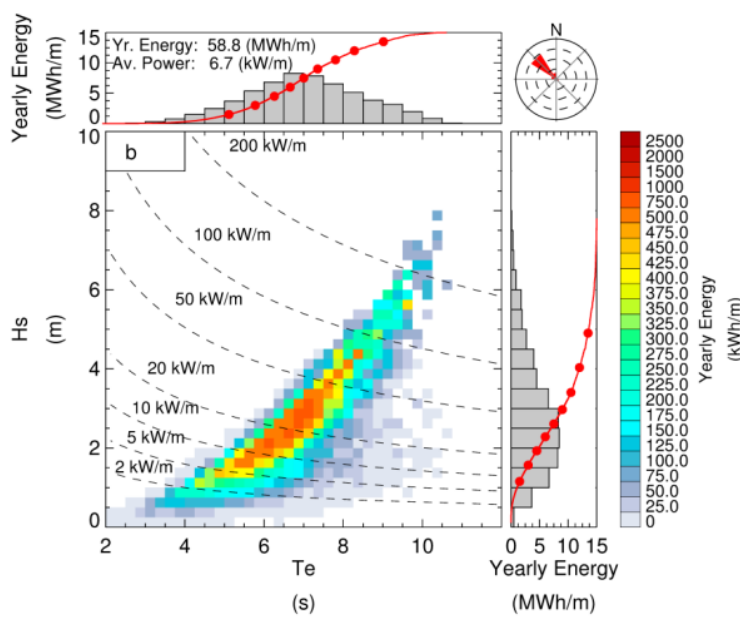

Fig. 1. Yearly average energy as a function of the wave height $H_{w}$ and of the period $T_{e}$ near Pantelleria island (Italy).

From the reading of the graph, a global resource of $60 \mathrm{MWh} / \mathrm{m}$ results with an average power of $6.7 \mathrm{Kw} / \mathrm{m}$.

The wave status of the sea is very variable determined by the factors that transfer energy to the wave like winds, seismic disturbances, and waves generated by the lunar and solar gravitational fields. Moreover, the seabed bathymetry or generic obstacles, influences shape and extension of the waves.

About that, various models are proposed in the literature which more or less fit the physical phenomenon [10-11]. Here, for simplicity, the "fully developed sea model" is taken into consideration. The characteristics of this wave model are reported in Tab. 1.

Table 1: Wave characteristics.

\begin{tabular}{cccccc}
\hline $\begin{array}{c}\text { Wind } \\
\text { velocity } \\
(\mathrm{km} / \mathrm{h})\end{array}$ & $\begin{array}{c}\text { Fetch } \\
(\mathrm{km})\end{array}$ & $\begin{array}{c}\text { Last } \\
(\mathrm{h})\end{array}$ & $\begin{array}{c}\text { Wave } \\
\text { height } \\
(\mathrm{m})\end{array}$ & $\begin{array}{c}\text { Wave } \\
\text { length } \\
(\mathrm{m})\end{array}$ & $\begin{array}{c}\text { Period } \\
(\mathrm{s})\end{array}$ \\
\hline 20 & 24 & 2.75 & 0.33 & 10.6 & 3.2 \\
\hline 40 & 176 & 11.50 & 1.80 & 39.70 & 6.2 \\
\hline 60 & 660 & 27.50 & 5.10 & 89.2 & 9.1 \\
\hline 80 & 1682 & 50.00 & 10.30 & 158.6 & 12.4 \\
\hline
\end{tabular}

From Tab. 1 it is possible to determine a relationship between the cycles number per minutes and the height of the wave.

$$
N_{c y}=11.92 H_{w}^{-0.38}
$$

For completeness, the next table reports the Douglas scale for determining the sea state

Table 2: State of the sea (wind sea).

\begin{tabular}{ccc}
\hline Degree & Height $(\mathbf{m})$ & Description \\
\hline 0 & no wave & Calm (Glassy) \\
\hline 1 & $0-0.10$ & Calm (rippled) \\
\hline 2 & $0.10-0.50$ & Smooth \\
\hline 3 & $0.50-1.25$ & Slight \\
\hline 4 & $1.25-2.50$ & Moderate \\
\hline 5 & $2.50-4.00$ & Rough \\
\hline
\end{tabular}




\begin{tabular}{ccc}
\hline 6 & $4.00-6.00$ & Very rough \\
\hline 7 & $6.00-9.00$ & High \\
\hline 8 & $9.00-14.00$ & Very high \\
\hline 9 & $14.00+$ & Phenomenal \\
\hline
\end{tabular}

\section{Description of the system}

The technical scheme of Fig. 2 illustrates the proposed system. The buoy (point absorber) can be put near the shore where the seabed allows the working. This buoy is connected to a piston pump at which transfers the wave motion. The piston pump delivers water in a pressurized tank partially filled by air, whose pressure can be maintained constant or changed to the desired value thanks an auxiliary compressor, able to restore the air losses. The hydraulic circuit closes on a Pelton turbine connected to an electrical generator. In more detail, the buoy is more extended in the horizontal plane and it is free to oscillate in the vertical direction (see Fig. 2), by following the wave crest.

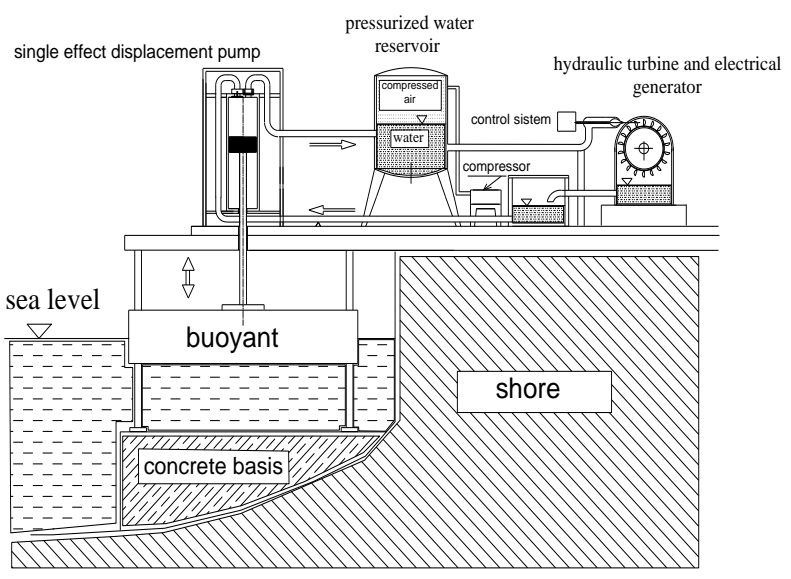

Fig. 2. System layout.

\section{Mathematical model of the buoy oscillations}

Making reference to Fig 3, the dynamic equation of the motion is given by the following equation [12]:

$$
\left(m_{b}+m_{a d d}\right) \ddot{z}+b \dot{z}=F_{p}+F_{w}-F_{A}
$$

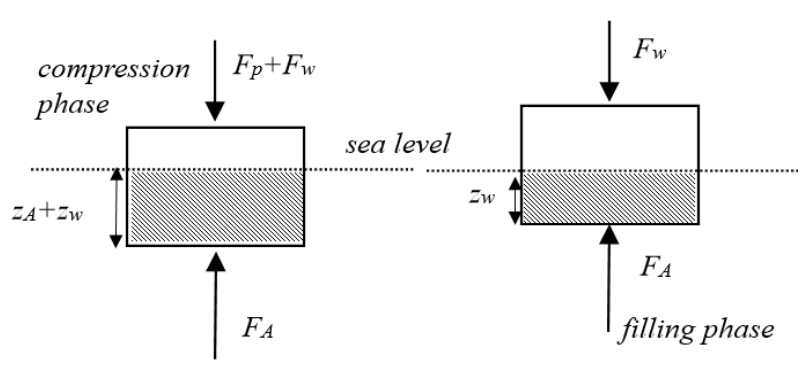

Fig. 3. Scheme of the forces on the buoy. where:

- $F_{A}=\rho g V_{z} \quad$ is the Archimedes's thrust

- $F_{p}=\frac{\pi D_{p}^{2}}{4} \rho g H_{m} \quad$ is the pressure force acted by the piston pump

- $F_{w}=g m_{b} \quad$ is the weight force

The solution of the differential equation will provide the vertical motion of the buoy, and consequently the excursion of the piston pump. It is worth pointing out that the piston pump will charge the water reservoir during the rising of the buoy (compression phase, see Figs. 3 and 4). Instead, during the filling phase (see Figs. 3 and 4), the piston pump is not connected to the reservoir and so the pressure force stops acting.

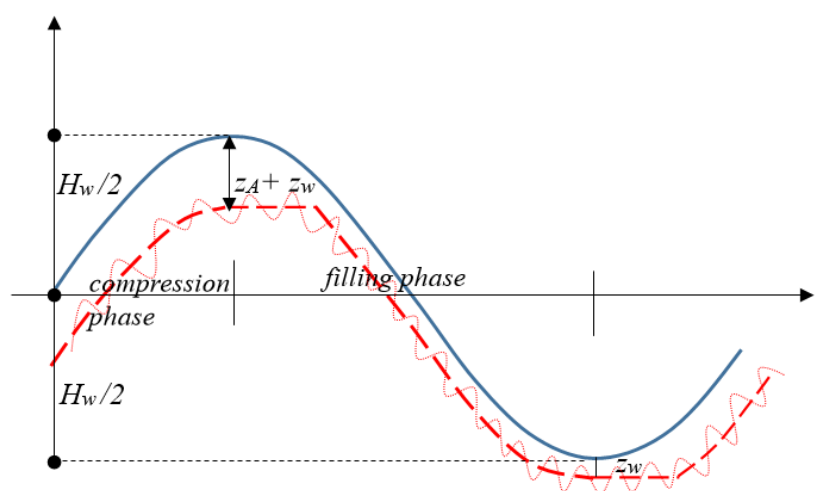

Fig. 4. Path of the buoy.

Fig. 4 illustrates the path of the buoy (red dashed line) under the action of a wave with height $H_{w}$, and the inertia secondary oscillations, derived from eq. 2 , which overlap on the red dashed line.

During the compression phase, the buoy sinks under the sea level of $z_{A}+z_{w}$ because of the reservoir pressure and its weight. During the filling phase, the buoy instead sinks by $z_{w}$. So the total excursion of the piston pump is:

$$
C_{o}=H_{w} / 2-z_{A}-z_{w}+H_{w} / 2+z_{w}=H_{w}-z_{A}
$$

\section{Sizing of the system}

Figure 5 summarizes the sizing procedure, starting from the wave height $\left(H_{w}\right)$, the buoy area $\left(A_{\text {buoy }}\right)$, the reservoir pressure $\left(H_{m}\right)$, the specific speed $(k)$ and the rated rotational speed $\left(n_{T}\right)$ of the Pelton Turbine, which in Fig. 5 are highlighted in the orange boxes. All the other devices/parameters consequently proportioned, are depicted in the blue boxes in the same figure.

In more detail, the height of the wave determines the number of cycles per minute $N_{c y}$ (see eq. 3 ) and also the stroke $C_{o}$ of the pump, while the piston area derives from the equilibrium equation of the buoy. So that, the displacement of the pump $V_{P}$ is found and consequently 
its flow rate $Q_{P}$. The latter has to be equal to the turbine flow rate $Q_{T}$. Now, by considering a fixed pressure of the reservoir $\rho g H_{m}$, and a specific speed $k$, besides a rated rotational turbine speed $n_{T}$, the Pelton turbine can be sized, i. e. its diameter $D_{T}$ and its nozzle diameter $D_{n}$.

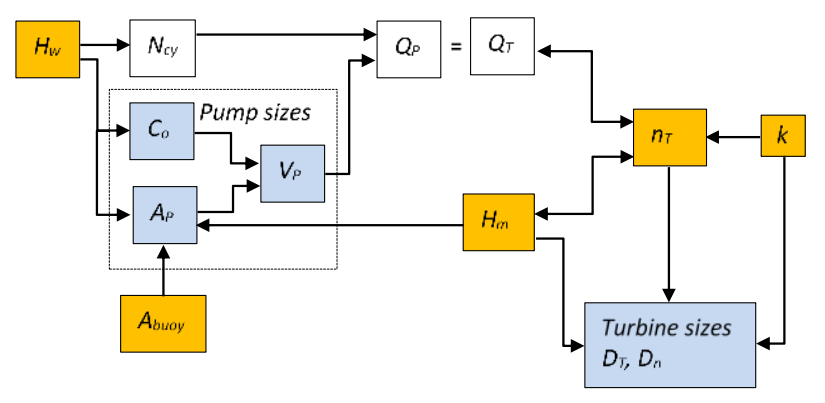

Fig. 5. Sizing procedure scheme.

In the following, the steps of the procedure above illustrated are explained in more detail.

\subsection{Piston pump and buoy sizing}

The sizing of these two devices is strictly correlated because of the equilibrium equation of the buoy, connected directly to the piston pump.

The first parameter considered is the flow rate elaborated by the pump, which is:

$$
Q_{p}=V_{P} \frac{N_{c y}}{60}=A_{p} C_{o} \frac{N_{c y}}{60}=\frac{\pi}{4} D_{p}^{2} C_{o} \frac{N_{c y}}{60}
$$

The piston area is given by imposing the equilibrium in the steady condition. From eq. 4, by neglecting the weight of the buoy, it results that:

$$
\frac{\rho g H_{m}}{\eta_{p}} A_{p}=\rho g z_{A} A_{\text {buoy }}
$$

By simplifying:

$$
A_{p}=\eta_{p} z_{A} \frac{A_{\text {buoy }}}{H_{m}}
$$

\subsection{Pelton choice}

The choice of the Pelton starts from the pressure level of the reservoir equal to $\rho g H_{m}$.

Taking into account the specific speed:

$$
k=\frac{1}{53} n_{T} \frac{\sqrt{Q}}{\left(g H_{m}\right)^{0.75}}
$$

whose optimal range is $[0 \div 0.18]$, the Pelton nominal flow rate can be determined as:

$$
Q_{T}=2809 k^{2} \frac{H_{m}^{\frac{3}{2}}}{n_{T}^{2}}
$$

Under the maximum efficiency conditions it results that:

$$
u \cong 0.5 c_{0}=0.5 \varphi \sqrt{2 g H_{m}}
$$

where

$c_{0}=\varphi \sqrt{2 g H_{m}}$ is the spouting velocity of the jet, $u$ is the peripheral velocity and $\varphi$ a velocity reduction coefficient.

The peripheral velocity depends on the Pelton diameter $D_{T}$ as follows:

$$
u=\frac{\pi D_{T} n_{T}}{60}
$$

So that the turbine diameter is expressed as:

$$
D_{T}=\frac{30}{\pi} \frac{\varphi}{n_{T}} \sqrt{2 g H_{m}}=42.2 \frac{\varphi}{n_{T}} \sqrt{H_{m}}
$$

In an analog way, the nozzle diameter $D_{n}$, can be determined by considering that the turbine flow rate can be expressed as:

$$
Q_{T}=\frac{\pi D_{n}^{2}}{4} c_{0}
$$

Then, by involving the specific speed of eq. 9 it results that:

$$
D_{n}=\frac{28.41}{n_{T}} \frac{k}{\sqrt{\varphi}} \sqrt{H_{m}}
$$

\subsection{Specific power of the system}

The waves energy is converted into electrical power, through the pump and the turbine working.

The pump power, by considering the pressure of the reservoir $H_{m}$ and the provided flow rate $Q_{P}$, is expressed by the following equation:

$$
\begin{aligned}
& P_{P}=\frac{\rho g Q_{P} H_{m}}{\eta_{P}}=\rho g \frac{\eta_{P}}{\eta_{P}} z_{A} \frac{A_{\text {buoy }}}{H_{m}} C_{o} \frac{N_{c y}}{60} H_{m} \\
& =\rho g z_{A} A_{\text {buoy }}\left(H_{w}-z_{A}\right) \frac{11.92 H_{w}^{-0.38}}{60}
\end{aligned}
$$

The power supplied by the pump is equal to that employed by the Pelton turbine for producing electrical energy, reduced by the turbine losses, so that one obtains:

$$
P_{T}=\eta_{T} \rho g z_{A} A_{\text {buoy }}\left(H_{w}-z_{A}\right) \frac{11.92 H_{w}^{-0.38}}{60}
$$

Instead the specific turbine power is:

$$
\frac{P_{T}}{A_{\text {buoy }}} \cong \eta_{T} 2000 z_{A}\left(H_{w}-z_{A}\right) H_{w}^{-0.38}
$$

By deriving the specific power with respect to $z_{A}$ a maximum value can be found for: 


$$
z_{A}=\frac{H_{w}}{2}
$$

The specific power of the system expressed in $\mathrm{kW}$ (see Fig. 6) considering the generator electrical loss, in the best condition, is given by:

$$
\frac{P_{\text {system }}}{A_{\text {buoy }}} \cong \frac{1}{2} \eta_{e l} \eta_{T} H_{w}^{1.62}
$$

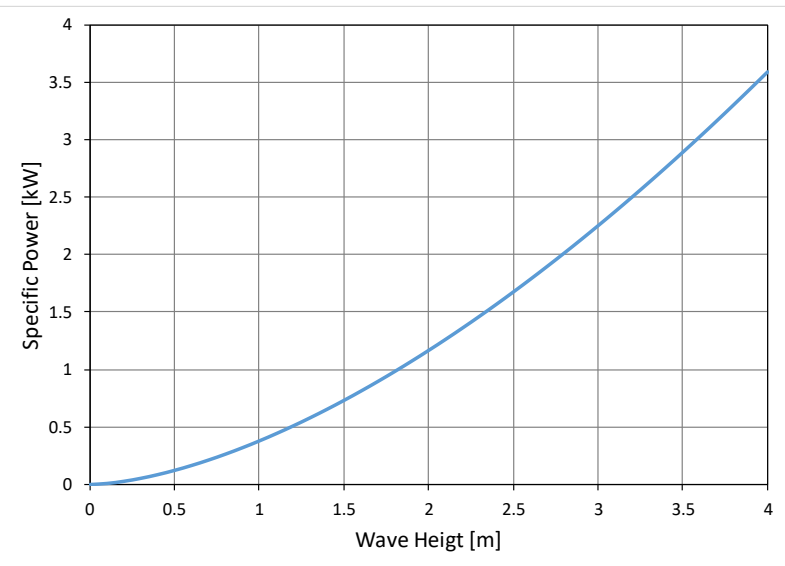

Fig. 6. Specific power of the system.

\section{Case study}

In this section, a system sizing is proposed with the aim to obtain small dimensions of all the components.

A key design parameter is the wave height. This parameter determines the size of the piston pump connected to the buoy, because the optimal stroke of the pump is equal to the wave design half height (eq. 19).

Fig. 7 reports an example of the probability distribution chart of the wave heights for the near shore region of Rio de Janeiro [12].

Making reference to Fig. 7, by choosing a wave height of $1 \mathrm{~m}$, the system will be able to work for $37 \%$ of the time at partial load and for $63 \%$ of the remaining time at full load (stroke of the pump equal to maximum value of $0.5 \mathrm{~m})$.

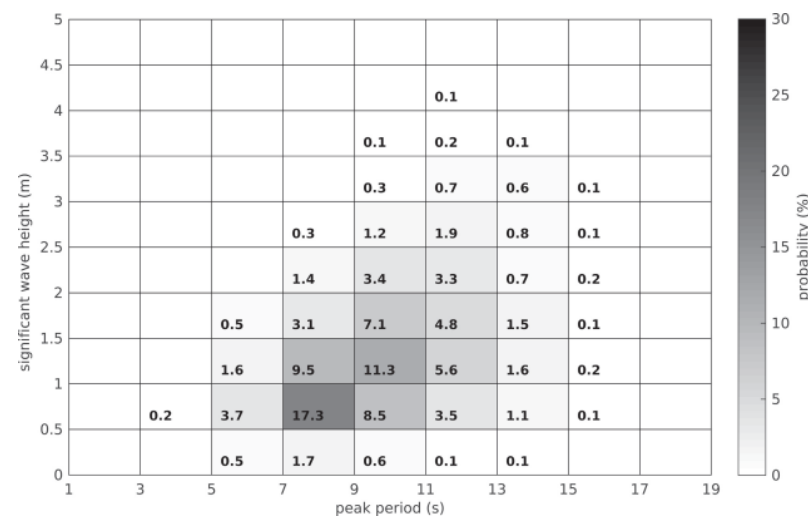

Fig. 7. Joint Probability distribution (\%) for the near shore region of Rio de Janeiro.
By considering that of Fig. 7 as a typical distribution, in a first rough configuration the design wave height is set equal to 1 .

All the system input parameters are reported in the next table:

Table 3: Input parameters of the system.

\begin{tabular}{|l|c|l|}
\hline Parameter & Symbol & Value \\
\hline Wave nominal height & $H_{w}$ & $1 \mathrm{~m}$ \\
\hline Buoy area & $A_{\text {buoy }}$ & $20 \mathrm{~m}$ \\
\hline Specific speed & $k$ & 0.09 \\
\hline Pressure reservoir & $H_{m}$ & $160 \mathrm{~m}$ \\
\hline Turbine rotational speed & $n_{T}$ & $3000 \mathrm{rpm}$ \\
\hline
\end{tabular}

These inputs allow all the components of the system to be sized. In fact, by applying eqs. $5,8,13,15,19$, the following values can be obtained:

Table 4: Output parameters of the system.

\begin{tabular}{|l|l|l|}
\hline Parameter & Symbol & Value \\
\hline Piston pump stroke & $C_{o}$ & $0.5 \mathrm{~m}$ \\
\hline Piston pump diameter & $D_{P}$ & $0.28 \mathrm{~m}$ \\
\hline Piston pump volume & $V_{P}$ & $30 \mathrm{l}$ \\
\hline Turbine diameter & $D_{T}$ & $0.168 \mathrm{~m}$ \\
\hline Turbine nozzle diameter & $D_{n}$ & $0.011 \mathrm{~m}$ \\
\hline
\end{tabular}

The flow rate elaborated by the system, is equal to $5.1 \mathrm{l} / \mathrm{s}$ (see eqs. 6, 10 and 14), while the nominal power amounts to $7 \mathrm{~kW}$.

In these conditions, the $C W R$ is equal to $33 \%, J$ being equal to $4.7 \mathrm{~kW} / \mathrm{m}$ (see eq. 1) and $D_{\text {buoy }}$ (characteristic size of the buoy) equal to $4.5 \mathrm{~m}$.

\subsection{Off design operations}

The Pelton turbine has the possibility of changing its flow rate without efficiency losses, by moving the needle of the nozzle so that the flowing area varies from zero (no wave) to the maximum value (design wave). All the intermediate waves (under $1 \mathrm{~m}$ ) imply proportional strokes of the piston pump, flow rates and consequent powers up to the design value of $7 \mathrm{~kW}$.

When the pump starts working, under the waves action, the nozzle feeding the turbine is closed. The water level of the reservoir rises until the pressure reaches the design value of 16 bar (160 m water column).

For guaranteeing this pressure value, an air mass of 20 $\mathrm{kg}$ at environment temperature, is compressed by the remaining part of water $\left(2 \mathrm{~m}^{3}\right)$, occupying a volume of 1 $\mathrm{m}^{3}$.

At this point, the nozzle of the turbine opens and the flow rate incoming is discharged on the turbine itself.

The successive increasing of the flow rate delivered by the pump, determined by waves height increases, would try to augment the air pressure. At purpose, the needle of the nozzle moves opening the nozzle area more, allowing the turbine flow rate to rise, so restoring the pressure level. 
When the nozzle area is completely open, successive increases of the flow rate, for waves higher than $1 \mathrm{~m}$ (design value), cannot be managed by the nozzle opening, but by greater pressure levels. For this reason the air mass is further compressed, occupying a minor volume, and the jet velocity, investing the Pelton turbine, augments as in eq. 11 .

In this case is worth pointing out that the efficiency will not be the maximum. In fact, the efficiency expression is equal to:

$$
\eta_{T}=2 \varphi^{2} \frac{u}{c_{o}}\left(1-\frac{u}{c_{o}}\right)(1+\psi \cos \beta)
$$

which finds a maximum value for $u / c_{o}=0.5$ if the velocity co remains to the design value, as in eq. 11 .

Increasing flow rates imply higher values of co and a decay of efficiency plus or minus consistent. This inconvenience can be overcome, by changing the rotational regime [13] so that the peripheral velocity $\mathrm{u}$ changes opportunely for maintaining unchanged the ratio $\mathrm{u} / \mathrm{co}$.

Finally, when the wave motion stops and the sea is still, the reservoir does not receive more water. In this condition the reservoir starts emptying. The water mass, flowing through the nozzle, lowers its level and the reservoir pressure decreases. Under a certain level, the turbine nozzle is closed and the reservoir remains filled partly by water and partly by air, by waiting until the sea becomes wavy again.

\section{Conclusions}

A hydraulic system made up of buoy, piston pump, pressurized reservoir and Pelton turbine has been sized, by following a procedure which aims to optimize all the geometrical parameters, starting from the design height wave, the reservoir pressure and the specific speed of the Pelton turbine.

The reservoir is conceived to operate at the same pressure for waves with height under $1 \mathrm{~m}$ (design value). For higher wave heights, the pressure of the reservoir together with the rotational regime of the turbine have to increase for maintaining the best efficiency conditions.

The system is conceived to be not excessively expensive, the design choices being addressed toward miniaturized components.

Anyway, the specific power of such a system is estimated equal to $0.38 \mathrm{~kW} / \mathrm{m} 2$, so that, by consider a point absorber with area equal to $20 \mathrm{~m} 2$, the nominal power is equal about to $7 \mathrm{~kW}$ with a capture width ratio of $33 \%$.

\section{References}

1. M. Noussan, R. Roberto, B. Nastasi, Energies 11, 650 (2018)

2. S. Barbarelli, M. Amelio, T. Castiglione, G. Florio, N.M. Scornaienchi, G. Lo Zupone, A. Cutrupi, Energy Convers Manag 87, 1124-33 (2014)
3. B. Drew, A.R. Plummer, and M. N. Sahinkaya. Proceedings of the IMechEA: Journal of Power and Energy, 223, 8, 887-902 (2009)

4. M.E. McCormick, Ocean Wave Energy Conversion, (Dover Publications, New York, NY, USA, 2007)

5. G. Thomas, Ocean Wave Energy: Current Status and Future Perspectives, J. Cruz, Ed. (Springer, Berlin, Germany, 2008)

6. S. Barbarelli, G. Florio, G. Lo Zupone, N.M. Scornaienchi, Renew Energy 129 Part A, 183-200, (2018)

7. D. Astiaso Garcia, F. Barbanera, F. Cumo, U. Di Matteo, B. Nastasi, Energies 9, 963 (2016)

8. P.B. Garcia-Rosa, J.P.V.S. Cunha, F. Lizarralde, American Control Conference Hyatt Regency Riverfront (St. Louis, MO, USA, 2009)

9. G. Lo Zupone, M. Amelio, S. Barbarelli, G. Florio, N.M. Scornaienchi, A. Cutrupi, Appl Energy 185, 1292-1302 (2017)

10. A. Guissard, C. Baufays, P. Sobieski, Remote Sensing of Environment 48, 1, 25-38 (1994)

11. P. Zwolan, K. Czaplewski, Scientific Journals, Maritime University of Szczecin 32, 104, 186-190 (2012)

12. M. Shadman, S.F. Estefen, C.A. Rodriguez, I.C.M. Nogueira, Renew Energy 115, 533-546 (2018)

13. S. Barbarelli, G. Florio, M. Amelio, N.M. Scornaienchi, Appl Energy 224, 717-730 (2018) 